\title{
RACISMO NA ESCOLA
}

Racism at school

http://dx.doi.org/10.21116/2019.2

\section{CERDAN, Marcelo Alves Cerdan}

Centro Universitário Max Planck

KODA, Fabiana

Centro Universitário Max Planck

RIBEIRO, Gracieli

Centro Universitário Max Planck

SANTOS, Tamires dos

Centro Universitário Max Planck

RESUMO: $O$ presente trabalho tem como objetivo, pesquisar questões relacionadas ao racismo, nas escolas e propor formas de abordá-lo. Orientando a sociedade, nas práticas ao combate do preconceito racial. Embora existam leis, que prevê punição, ainda sim há comportamentos de forma camuflada, com interferências desde á época do colonialismo, até os dias atuais. Foi utilizado como métodos: pesquisas de artigos científicos, livros e pesquisas on-line, visando destacar a correção da desigualdade social, através das ações afirmativas, sendo a população negra a que mais sente os efeitos do desemprego, da violência e da falta da representatividade da sua cultura. Porém, cabe a nós educadores, buscar cada vez mais estar informados e consciente sobre o assunto, para que possamos promover a diversidade da cultura e a desconstrução da imagem estereotipada dos negros.

Palavra-chave: Racismo na escola; Cultura; Aprendizagem.

Abstract: The present work aims to investigate issues related to racism in schools and to propose ways of addressing it. Orienting the society, in the practices to the combat of the racial prejudice. Although there are laws of punishment, there are still some behaviors in a camouflaged way, with interference from the colonial era to the present day.

It was used as methods: research on scientific articles, books and online research, aiming the correction of social inequality, through actions to policies, being a black population that most feels the violence, violence and lack of representativeness of their culture.

Moreover, it is up to us educators, to research more and more information and to obtain more information on the subject, so that the media promote a culture and a deconstruction of the stereotyped image of the blacks.

Keywords: Racism in school; Culture; Learning. 


\section{INTRODUÇÃO}

O presente trabalho busca chamar a atenção à importância de se trabalhar questões raciais na sociedade e nas escolas, em especial com relação às práticas de preconceito, de racismo e a injuria racial. Enquanto o primeiro está relacionado a opiniões preconcebidas em relação a determinada pessoa ou grupo; o segundo, alicerça-se na ideia de que a humanidade pode ser dividida em raças e que elas possuem uma hierarquia; já a injuria racial é a ação de ofender alguém tendo como referência a sua cor, crença, etnia ou condições.

A existência e persistência do racismo no Brasil e seus frutos estão estritamente implicadas com a escravidão no Brasil, que fez parte de nossa realidade histórica e social desde a primeira metade do século XV e 1888, quando foi abolida institucionalmente por decreto assinado pela princesa Isabel. Acontece que após a abolição, os negros foram "abandonados" e excluídos pela sociedade, já que não houve políticas públicas que olhassem para sua inserção social, política e econômica, deixando-os às margens da sociedade.

Após mais de um século do o fim da escravidão, percebeu-se que somente as lutas dos movimentos sociais não seriam suficientes para minimizar as heranças deixadas por nossa história aos descendentes dos escravizados, então, o governo federal criou políticas afirmativas, cujo objetivo é minimizara desigualdade social e econômica pautada pela cor de pele, a mais efetiva - e polêmica - é a lei de cotas raciais, que reserva uma porcentagem de vagas em universidades públicas a quem se autodeclarar afrodescendente. No entanto o assunto não é ponto pacífico, pois há grupos que são contrárias e outros que são favoráveis às cotas raciais.

Além das cotas, outra medida tomada, pelo governo brasileiro, para atenuar as consequências históricas do nosso passado escravista sob a população afrodescendente, foi a promulgação da Lei 10.6999/2003, que institui a obrigatoriedade e inclusão de conteúdos sobre a cultura afro nos currículos escolares e universitários, no entanto, pode-se constatar que para muitas instituições educacionais e profissionais da educação, a Lei não passa de letra morta. O que é lamentável, pois acredita-se que a escola é um dos principais 
espaços sociais para se trabalhar e combater o racismo e a referida Lei, e o que ela propõe, é um importante instrumento para que isso seja efetivado.

Os textos que segues, abordará com mais profundidade os temas destacados acima, espera-se que, de alguma maneira, ela sirva como um convite para que possamos fazer da Educação uma ferramenta de transformação e que nossa sociedade não paute as oportunidades de seus cidadãos pela cor de sua pele e por sua origem étnica.

\section{O QUE É RACISMO E INJURIA RACIAL}

Na sociedade brasileira junto ao ambiente escolar é muito comum a ocorrência de práticas preconceituosas, racistas e de injuria racial, que são, ao mesmo tempo, resultado e alimentador de muitos problemas sociais, cultural, econômico e psicológico. Apesar de ser grande a ocorrência, há muita confusão no entendimento do significado de cada uma dessas práticas, dessa maneira, crê-se ser importante trazer ao texto a suas definições.

> Preconceito: É uma opinião preconcebida em relação à determinada pessoa ou grupo, que não é baseada em uma experiência real ou na razão.

> Racismo: é acreditar que algumas raças são superiores às outras.

> Injuria racial: É ação de ofender alguém baseado em sua cor, crença, etnia ou condição enquanto idoso ou portador de deficiência.

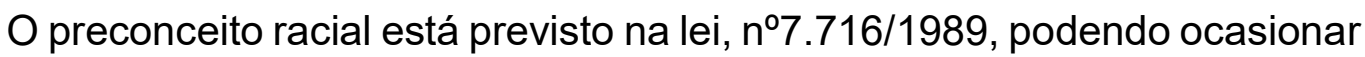
a pena de reclusão de dois a cinco anos. No entanto o preconceito não se restringe apenas questões raciais, ele se retrata também a homofobia, transfobia xenofobia, bullying, entre outros.

O racismo se baseia na ideia de que existem diferentes raças humanas e que elas são hierarquizadas, sendo a "raça branca", a superior, enquanto as negras, asiáticas e os indígenas, inferiores. A classificação das raças se apoia em diferenças de fenótipos: cor da pele, formato do crânio, aparência física, etc. (PAVAN, 2016)

Segundo a pesquisadora Maria Aparecida da Silva, em artigo sobre racismo na escola:

O preconceito é basicamente uma atitude negativa (é necessário que haja algum referente positivo para 
comparação) com relação a um grupo ou pessoa, baseando-se num processo de comparação social em que o grupo da pessoa preconceituosa é considerado uma psicológica que acentua sentimentos e atitudes endereçados a um grupo como um todo ou a um indivíduo por ser membro dele.

A discriminação, por sua vez, é a manifestação comportamental do preconceito, ou seja, é a materialização da crença racista em atitudes que efetivamente limitam ou impedem o desenvolvimento humano pleno das pessoas pertencentes ao grupo discriminado e mantem os privilégios dos membros de grupo discriminador à custa do prejuízo dos participantes do grupo discriminado. (SILVA, 2001 p. 75)

A injuria racial é um crime que consiste na ofensa à honra de terceiros, com utilização de elementos referentes à sua etnia e cor; sua prática está prevista no artigo 140 SS $3^{\circ}$ título I, capitulo V da parte especial do Código Penal Brasileiro - "Dos crimes contra a Honra".

Por fim, pode-se dizer que o crime de injúria racial e racismo, que tem relações estreitas com o preconceito, apesar de serem parecidos e confundidos na sociedade, possuem significados e penas bem distintos. (PAVAN, 2016)

Contudo, tanto racismo, preconceito e injuria são heranças históricas da sociedade brasileira, que teve suas relações sociais e econômicas alicerçadas na escravidão de pessoas do continente africano e seus descentes cuja história atravessou séculos e possuem nos dias de hoje.

Dessa maneira, segue abaixo uma breve história da escravidão negra no Brasil, para que o leitor entenda as práticas racistas como galhos de uma árvore semeada em solos passados.

\section{A ESCRAVIDÃO NEGRA NO BRASIL}

\section{Da chegada ao fim da escravidão.}

A escravidão do Brasil ocorreu entre os séculos XVI a XIX. Inicialmente, os colonos portugueses escravizaram os índios, no entanto, a política religiosa e o interesse por lucros no comércio de cativos conduziam para o fim da escravidão indígena, fazendo com que as mãos de obras escravas viessem exclusivamente do continente africano. (ALENCASTRO, 2000). 
Estima-se que entre 1538 e 1850, foram desembarcados aproximadamente 3,6 milhões de africanos nas costas Brasileiras (CÉLIA, 2007), cabe lembrar que muitos que tinha como destino a vida servil do lado de cá do atlântico nem se quer desembarcaram, pois, a taxa de mortalidade durante a travessia era bastante expressiva, pois faltavam condições mínimas de higiene, alimentação e cuidados com a saúde. (ALENCASTRO, 2000)

A travessia atlântica do navio foi retratada por alguns artistas da época, como, por exemplo, na pintura "Navios negreiro", de Johann Motriz Rugendas. (RUGENDAS, SD)

Figura 1

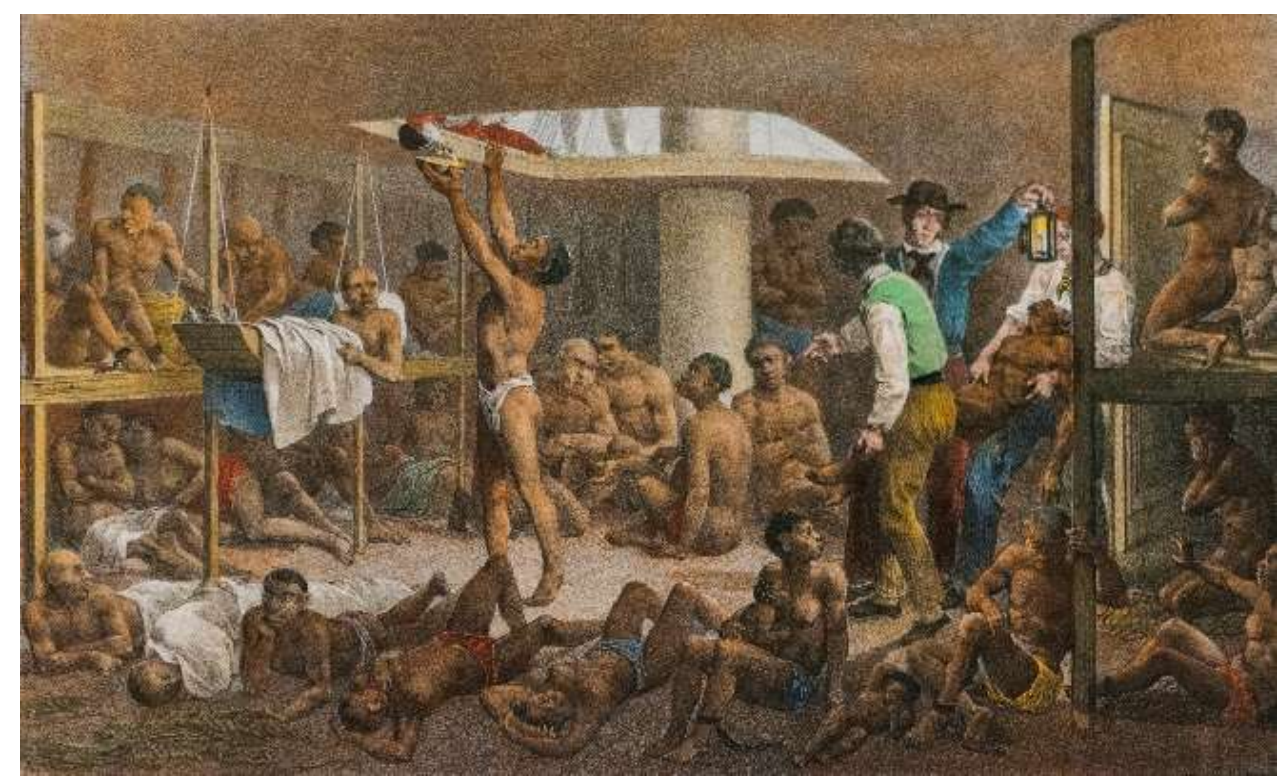

Johann Moritz Rugendas. Navio negreiro, $1830^{1}$

Pode-se perceber, como nas imagens, as dificuldades enfrentadas pelos africanos escravizados. O espaço era pequeno, eles estavam expostos a doenças como a varíola, diarreia e escorbuto, entre outras. Sem falar na privada de alimento e águia potável (RAMBELLI, 2015, p.55).

$\mathrm{Na}$ chegado ao Brasil, os africanos ficavam em quarentena para se recuperar da desgastante viagem, que durava em média 60 dias, pois precisavam estar bem apresentados fisicamente para seus novos "donos', que

${ }^{1}$ RUGENDAS, Johann Maritz. Navio negreiro. Disponível em:

<https://jogodavidaweb.wordpress.com/2017/03/29/johann-moritz-rugendas/\#jp-carousel-2151> Acessado em: 18. Abril. 2018 
os adquiriam em compras diretas e em leilões nas zonas portuárias". (MATTOSO, 2003)

O mercado de escravo brasileiro mais famoso era o do Valongo, localizado na cidade do Rio de Janeiro. Entretanto, o tráfico desembarcava suas mercadorias humanas em outras regiões, conforme ilustra o mapa abaixo²:

Figura 2

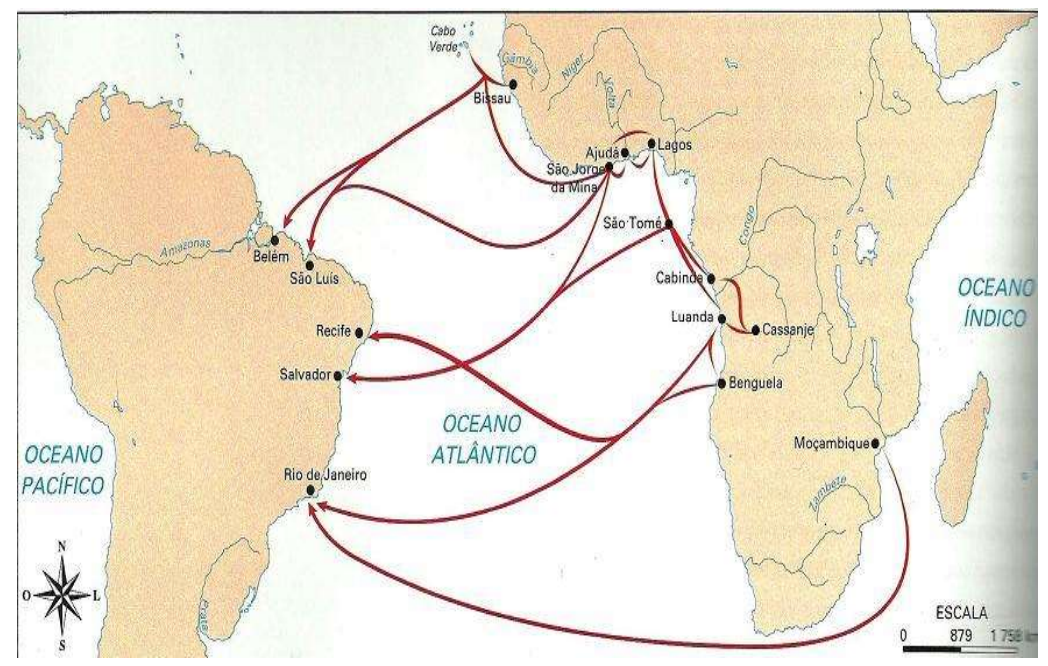

FONTE: Mapa representando o comércio triangular: Portugal - Brasil - África.

Abaixo, têm-se representações de como poderia ser feita essas compras e vendas, representada na pintura do viajante Jean Baptista Debret.

Figura 3

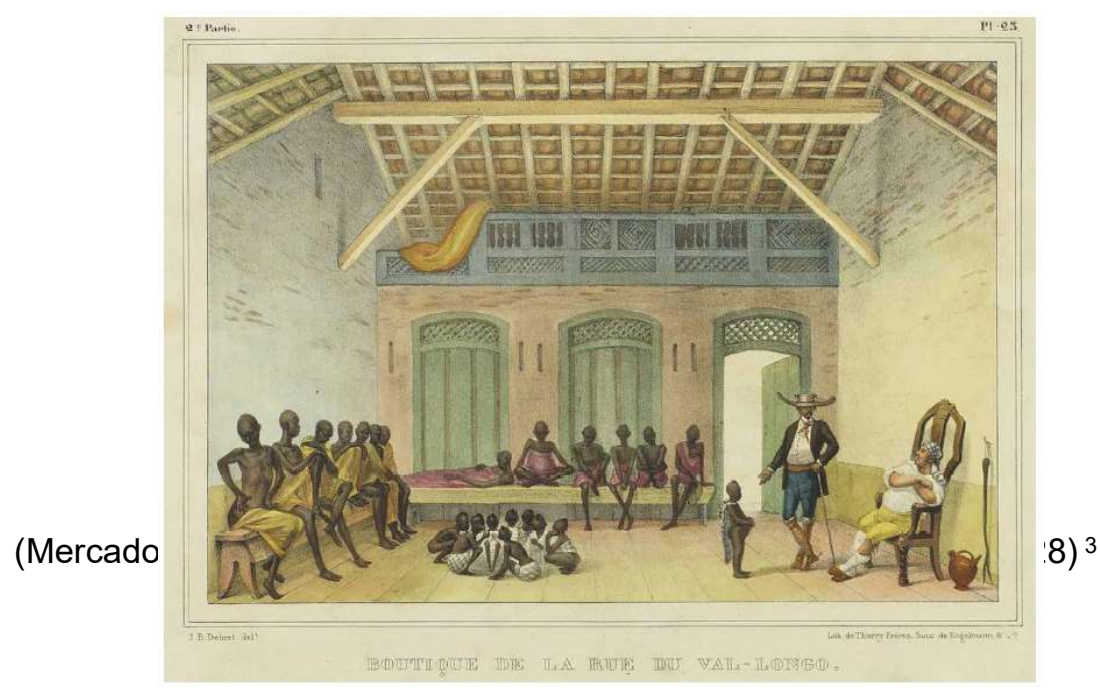

2 Disponível em: <http://diretodosmanguezais.blogspot.com.br/p/dia-de-negro.html> Acesso em abril. 2018 às $12 \mathrm{~h} 12$

3 HAAG, Carlos. Os ossos que falam. Disponível em: < http://revistapesquisa.fapesp.br/2011/12/24/ossos-que-falam/ > Acesso em abril. 2018 às $12 \mathrm{~h} 12$ 
Após serem vendidos, seguiam para os seus destinos finais, onde iriam trabalhar de sol a sol, eles eram como salientou o Padre Antonil, "as mãos e os pés do senhor de engenho, porque sem eles no Brasil não é possível fazer, conservar e aumentar fazenda" (ANTONIL, 1982). A maioria recebia alimentação de péssima qualidade, sendo submetidos a privações e alguns eram punidos com castigos dolorosos. No entanto, apesar disso, muitos escravizados foram capazes de superar suas condições e criar estratégias de sobrevivência econômica, social e cultural. A pintura abaixo mostra africanos escravizados trabalhando na produção de açúcar.

Figura 4

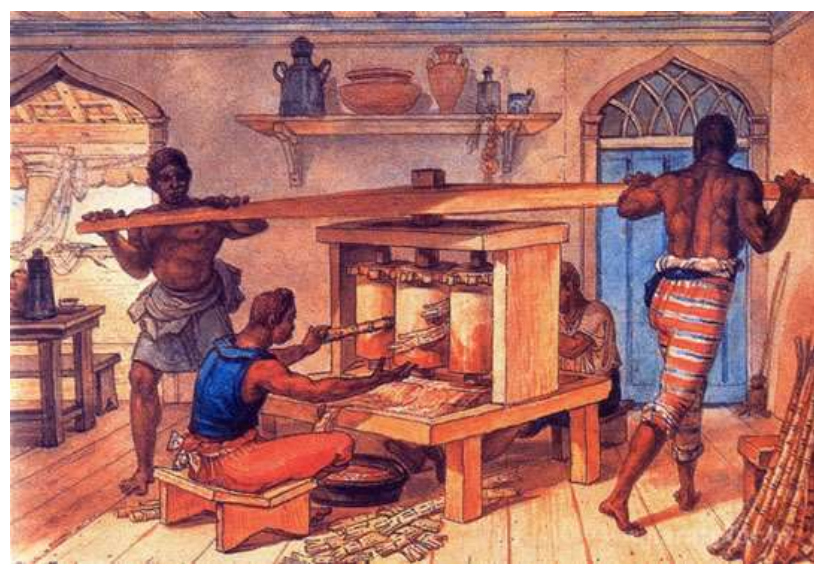

Pequena Moenda de Cana Portátil, Jean Baptist Debret, 18274

Mas nem só o trabalho preenchia a rotina dos escravizados, como nos lembra do viajante Rugendas, "nos domingos ou dias de festas, tão numerosos que até absorvem mais de cem dias do ano, os escravos são dispensados de trabalhar para seus senhores e podem descansar ou trabalhar para si próprio". (RUGENAS, S/d, p.238). Na obra abaixo, nota-se os escravos fazendo uso do tempo que tinham para si para se divertir, era o momento em que também faziam seus "rituais" como danças lembrando-se e praticando sua cultura (CERDAN, 2013).

\footnotetext{
${ }^{4}$ História de São Paulo. Disponível em: < https://historiadesaopaulo.wordpress.com/escravidao-negra-em-sao-paulo-e-no-brasil/> Acesso em abril. 2018 às $12 \mathrm{~h} 12$
} 
Figura 5

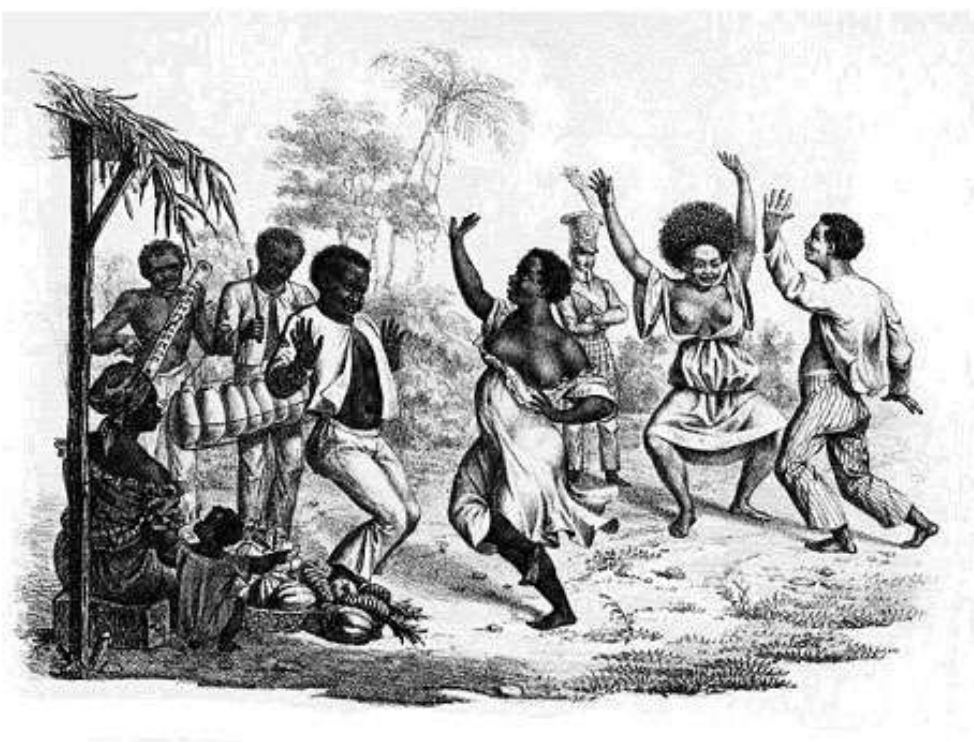

Joham Baptista Spix e Karl Philipp Von Martins (O batuque em São Paulo, 1817) ${ }^{5}$

A escravidão brasileira foi oficialmente extinta em 13 de maio de 1888, após a decretação da Lei Áurea, assinada pela princesa Isabel. Dos pouco mais de 500 anos de história oficial, o Brasil participou por quase 400 anos sob o regime de escravidão. O país, no continente americano, foi o último a abolir a escravidão.

A tabela abaixo mostra os últimos países a abolir a escravidão no continente americano ${ }^{6}$ :

\begin{tabular}{|l|c|}
\hline HAITI & 1804 \\
\hline CHILE & 1823 \\
\hline BOLIVIA & 1826 \\
\hline MÉXICO & 1829 \\
\hline ARGENTINA & 1853 \\
\hline ESTADOS UNIDOS & 1863 \\
\hline BRASIL & 1888 \\
\hline
\end{tabular}

O fim institucional da escravidão no Brasil aconteceu em 1888, a princesa Isabel, assinou a lei Aurea mesmo com o fim da escravidão, os negros continuaram marginalizados, recém-libertos passaram dias difíceis, sem acesso

\footnotetext{
${ }^{5}$ SPIX, Joham Batista, MARTINS, Karl Philipp Von. O batuque em São Paulo. Disponível em: <http://www.iar.unicamp.br/disciplinas/am540_2003/edu/produto/escravidao/resistencia2.htm> Acesso em abril. 2018 às $12 \mathrm{~h} 12$

6 Geledes. Datas da abolição da escravidão nos países americanos. Disponível em: $<$ https://www.geledes.org.br/datas-da-abolicao-da-escravidao-nos-paises-americanos/> Acesso em abril. 2018 às $12 \mathrm{~h} 12$
} 
as terras, vítimas de muito preconceito, enfim, deixados a própria sorte, situações que reflete na condição social da população negra brasileira ainda hoje.

POLÍTICAS AFIRMATIVAS PARA COMBATER A DESIGUALDADE RACIAL E SOCIAL

Desempregos da população negra no Brasil.

No Brasil, a população negra é a que mais sente os efeitos do desemprego, da violência e da falta representatividade. Segundo dados pelo IBGE dos 12,3 milhões de desempregados, cerca de $64 \%$ são negros e pardos. A desigualdade está presente também na renda da população brasileira, enquanto pessoas de cor branca recebem em média um salário de $R \$ 2.660,00$; as negras e pardas recebem $\mathrm{R} \$ 1.480,00$, como mostra os dados dispostos no gráfico abaixo?.

Gráfico 1:

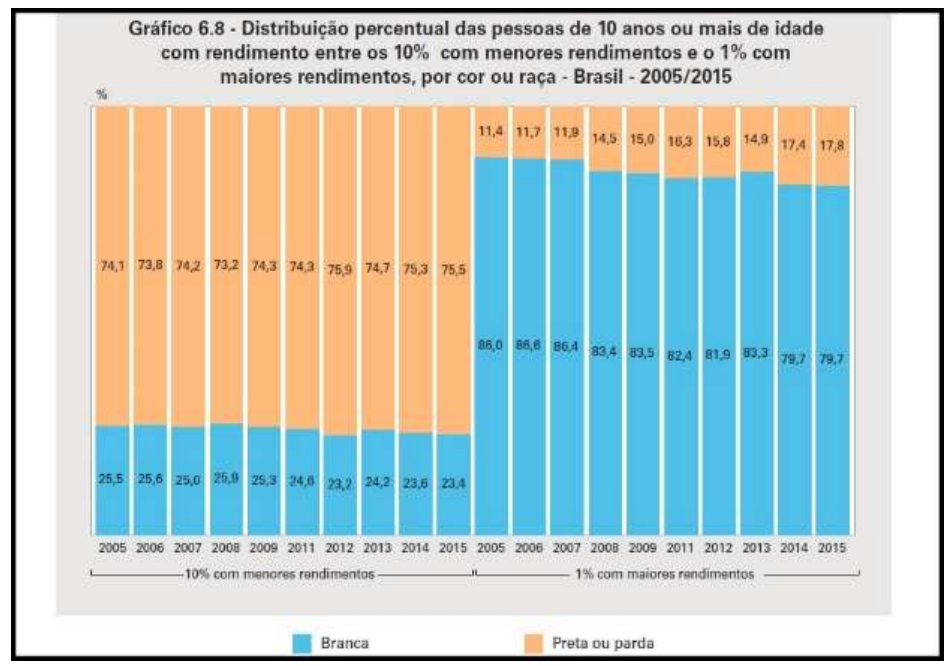

DADOS DO IBGE - distribuição das pessoas-

\section{COTAS E SUA IMPORTÂNCIA}

\footnotetext{
7 Jornal popular. Negros no mundo do trabalho. Disponível em: $<$ https://pclcprio.wixsite.com/vozoperaria/single-post/2017/04/01/Quest\%C3\%A3o-racial-e-oracismo-em-estat\%C3\%ADsticas-oficiais > Acesso em abril. 2018 às $12 \mathrm{~h} 12$
} 
As cotas raciais fazem parte de políticas públicas e de ações afirmativas, cujo objetivo é corrigir e compensar as desigualdades sociais presentes na sociedade e acumuladas historicamente, no caso brasileiro, o primeiro grupo a ser contemplado, com essa preocupação, é o de afrodescendentes, pois há um entendimento que o passado escravocrata brasileiro submeteu seus ascendentes a condições sociais, materiais e jurídicas bastante desfavorável aos demais grupos sociais e que, mesmo com a abolição da escravidão, os negros continuaram sendo descriminados pela cor.

As políticas de cotas raciais em concursos públicos e universidades não foram inventadas no Brasil, já tinham sido implantadas em alguns países onde houve escravidão; os EUA foram os primeiros a fazer uso de políticas afirmativas para combater a desigualdade pela cor da pele, meio século antes do Brasil, mais especificamente no ano de 1960. (DIWAN, 2007)

A primeira ação brasileira, de fato, deu-se em junho de 2014, quando a Universidade de Brasília (UNB) adotou o sistema de cotas raciais, fazendo valer uma determinação legal, presente na Lei 12.711 , a qual determina que $50 \%$ das vagas das universidades e junto as instituições federais de educação superior sejam destinadas a estudantes de escolas públicas, $25 \%$ para negros, pardos e indígenas, conforme pode se ler no texto da lei, transcrito abaixo:

(...) A PRESIDENTA DA REPÚBLICA Faço saber que o Congresso Nacional decreta e eu sanciono a seguinte Lei: Art. $1^{\circ}$ As instituições federais de educação superior vinculadas ao Ministério da Educação reservarão, em cada concurso seletivo para ingresso nos cursos de graduação, por curso e turno, no mínimo $50 \%$ (cinquenta por cento) de suas vagas para estudantes que tenham cursado integralmente o ensino médio em escolas públicas." Parágrafo único. No preenchimento das vagas de que trata o caput deste artigo, $50 \%$ (cinquenta por cento) deverão ser reservados aos estudantes oriundos de famílias com renda igual ou inferior a 1,5 salário-mínimo (um salário-mínimo e meio) per capita. Art. $5^{\circ} \mathrm{Em}$ cada instituição federal de ensino técnico de nível médio, as vagas de que trata o art. $4^{\circ}$ desta Lei serão preenchidas, por curso e turno, por autodeclarados pretos, pardos e indígenas e por pessoas com deficiência, nos termos da legislação, em proporção ao total de vagas no mínimo igual à proporção respectiva de pretos, pardos, indígenas e pessoas com deficiência na população da unidade da

\footnotetext{
${ }^{8}$ Disponível em: < http://www.utfpr.edu.br/futuros-alunos/sisu/sisu-2017-1/lei-no-12-711-de-29de-agosto-de-2012 > Acesso em abril. 2018 às $12 \mathrm{~h} 12$
} 
Federação onde está instalada a instituição, segundo o último censo do IBGE. (Redação dada pela Lei $n^{\circ}$ 13.409, de 2016) Parágrafo único. No caso de não preenchimento das vagas segundo os critérios estabelecidos no caput deste artigo, aquelas remanescentes deverão ser preenchidas por estudantes que tenham cursado integralmente o ensino fundamental em escola pública. Art. $6^{\circ} \mathrm{O}$ Ministério da Educação e a Secretaria Especial de Políticas de Promoção da Igualdade Racial, da Presidência da República, serão responsáveis pelo acompanhamento e avaliação do programa de que trata esta Lei, ouvida a Fundação Nacional do Índio (Funai). Art. $7^{\circ}$ No prazo de dez anos a contar da data de publicação desta Lei, será promovida a revisão do programa especial para o acesso às instituições de educação superior de estudantes pretos, pardos e indígenas e de pessoas com deficiência, bem como daqueles que tenham cursado integralmente o ensino médio em escolas públicas. (Redação dada pela Lei $n^{\circ} 13.409$, de 2016) Art. $8^{\circ}$ As instituições de que trata o art. $1^{\circ}$ desta Lei deverão implementar, no mínimo, 25\% (vinte e cinco por cento) da reserva de vagas prevista nesta Lei, a cada ano, e terão o prazo máximo de 4 (quatro) anos, a partir da data de sua publicação, para o cumprimento integral do disposto nesta Lei. Art. $9^{\circ}$ Esta Lei entra em vigor na data de sua publicação.

As cotas são uma ferramenta importantes de reparação às desigualdades que a população negra e seus descendentes, que representa $54 \%$ da população brasileira, vêm sofrendo ao longo da história, especialmente pelas heranças deixadas pelo passado escravista. Bastam averiguar as informações censitárias sobre população negra brasileira com relação à educação, cultura, salários, empregos e representações institucionais e políticas, nos gráficos que seguem abaixo: 
Gráfico 2:

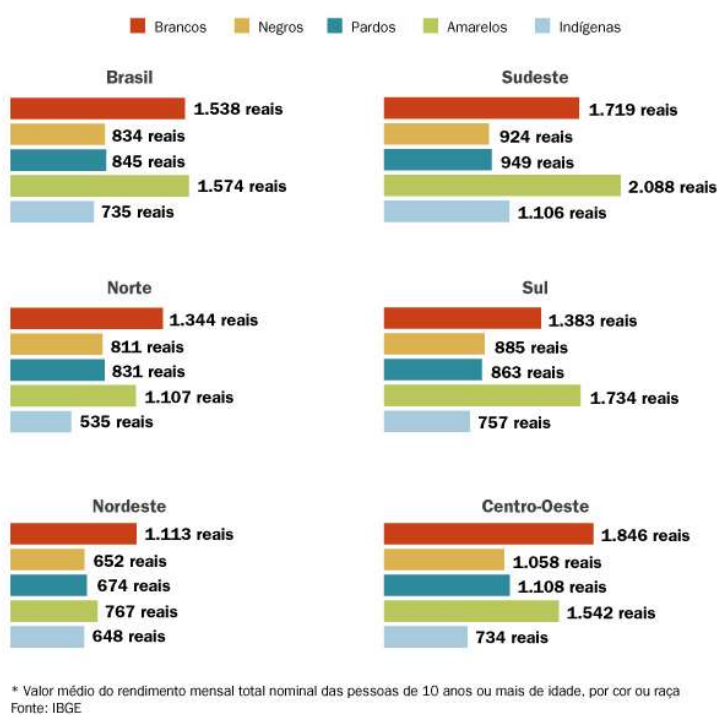

Brancos ganham quase o dobro que negros e pardos ${ }^{9}$.

No entanto, o assunto não é ponto pacífico na sociedade brasileira; há grupos que são contrários, e outros que são favoráveis às cotas raciais nas universidades públicas. O principal argumento daqueles que são contrários é de que as cotas reforçam o preconceito e discriminação racial, pois acabam reafirmando a princípio norteador do racismo, que é a ideia que os negros são inferiores. Entretanto, essas pessoas, segundo os favoráveis às cotas, desconsideram que o Brasil tem uma "divida" com os negros, tanto pela condição a que foram submetidos como pela importância que tiveram na formação material e cultural do Brasil.

Há ainda o fato, de que no Brasil, a maioria da população pobre são pessoas negras, o que força a procurarem emprego ainda em fase escolar, aumentando a evasão escolar entre a população negra, como pode se ver no gráfico abaixo, que torna perceptível a ideia que, conforme avança o nível de escolaridade, diminui a participação de negros nas instituições educacionais brasileiras.

\footnotetext{
${ }^{9}$ Disponível em: <https://deglutindopensamentos.files.wordpress.com/2013/02/graf2-original.jpg, capturado em 06/04/2018 - 16:36)
} 
Gráfico 3:

Distribuição percentual de estudantes por curso, segundo sexo e cor/raça

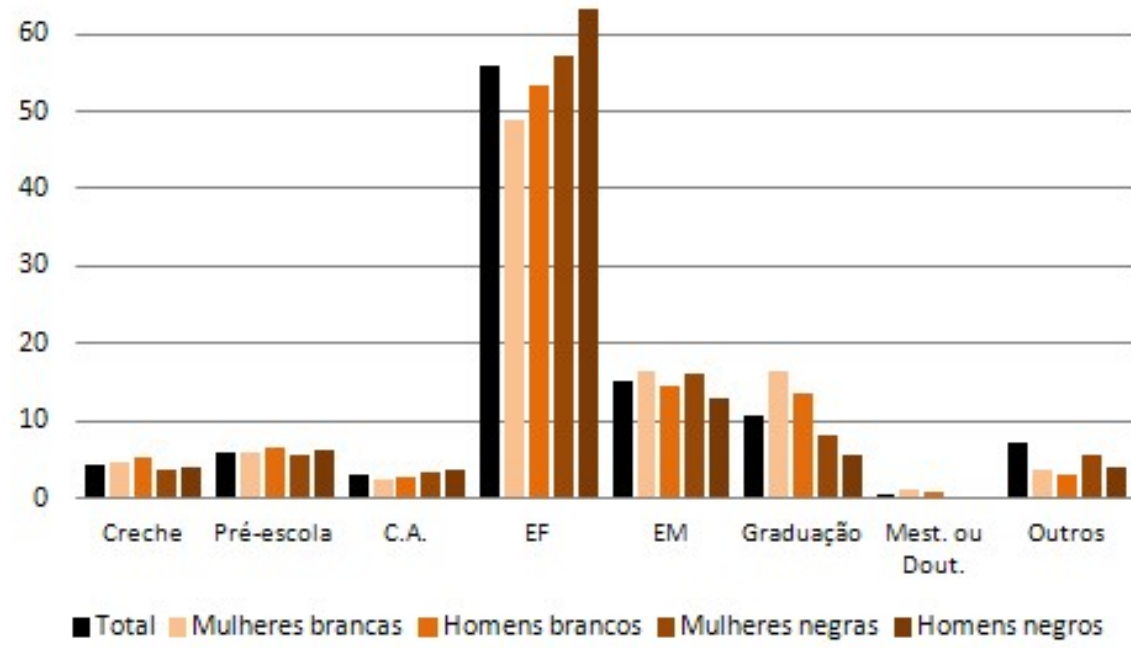

Distribuição percentual dos/as estudantes por curso frequentado, segundo o sexo e cor/raça. Legenda: C.A. (Classe de Alfabetização), EF (Ensino Fundamental), EM (Ensino Médio). (Fonte: PNAD 2009, baseado em Rosemberg \& Madsen, 2011 10 )

A autora do artigo - Fúlvia Rosemberg - de onde foi retirado o gráfico, também chama a atenção para outra questão envolvendo a vida escolar dos alunos negros do Ensino Fundamental, segundo ela,

A concentração de homens negros no Ensino Fundamental não deve ser comemorada! Isto não significa que eles estejam acessando mais o ensino fundamental. Significa, pelo contrário, que eles não estão conseguindo sair dessa etapa de ensino. Enquanto as mulheres brancas passam pelo fundamental, pelo médio e chegam às faculdades, os meninos negros ficam retidos no fundamental, o que leva ao aumento da sua proporção nesta etapa. (ROSEMBERG)

A evasão escolar não pode ser desconsiderada como fator condicionador da desistência de alunos, entretanto, como o foco da presente pesquisa está focada nas relações socioculturais e político do racismo escolar, não será dada

10 Disponível em: <(https://ensaiosdegenero.wordpress.com/tag/fulvia-rosemberg/, capturado em 06/04/2018 - 16:43) Distribuição percentual dos/as estudantes por curso frequentado, segundo o sexo e cor/raça. Legenda: C.A. (Classe de Alfabetização), EF (Ensino Fundamental), EM (Ensino Médio). 
a atenção devida a questão, há inúmeros estudos interessantes que abordam a questão.

As políticas de cotas seria então uma maneira de dar à população negra condições de se inserir de maneira justa nos mecanismos sociais e econômicos e para que isso possa se concretizar, ela precisa acessar alguns mecanismos necessários, e a escola pode ser considerada o principal deles.

O professor de cultura Brasileira, Marcos Minui, doutor pela Pontifícia universidade Católica do Rio Grande do Sul (PUCRS), por exemplo, é a favor e justifica seu posicionamento segundo ele:

Tenho opinião favorável, no sentido de que democratiza o acesso, considerando nossas grandes desigualdades sociais. Pode-se criticar o sistema ou tentar encontrar outras formas de democratização de acesso mais eficazes, mas o importante é que os mecanismos existentes refletem uma preocupação de resolver o problema. ${ }^{11}$

Quando o negro é tolerado em outros ambientes, como universidades, na política, ou em lugares que tem classe média mais elevada, passa a incomodar a elite branca. A aplicação da Lei 12.711/2014 e seus desdobramentos podem surtir efeitos morais e psicológicos positivos entre os alunos negros e pardos do Ensino Fundamental e Médio, em especial quanto a não desistirem dos estudos, pois quanto mais negros frequentarem a universidade, ao longo prazo, menos desigualdade vai ter, assim, as futuras gerações de negros terão seus pais com melhores condições econômicas, assim não precisarão trabalhar tão cedo e largar a escola; também, conforme as crianças negras virem mais pessoas da sua cor entrando em faculdade e tendo profissões que dependem de faculdade, terão mais desejos de seguir estudando, pois estarão se vendo representadas naqueles espaços.

Mas se as cotas têm trazido e pode trazer mais benefícios à população negra, também têm despertado reações por parte de alunos brancos e professores das universidades, alguns alegam que esse sistema acaba baixando o desempenho da comunidade acadêmica, entretanto, alguns estudos têm demonstrado que essas afirmações não passam de preconceitos.

\footnotetext{
${ }^{11}$ Redação online. Disponível em: https://redacaonline.com.br/blog/tema-de-redacao-cotas/
} 
Muitas vezes o debate foge ao controle e às esferas do debate racional, não poucas vezes, algumas pessoas contrárias a política de compensação racial têm se manifestado de com argumentos de caráter racista e bastante ofensivo. Abaixo segue umas imagens que retratam essas reações em algumas Instituições de Educação Superior. ${ }^{12}$

Figura 6

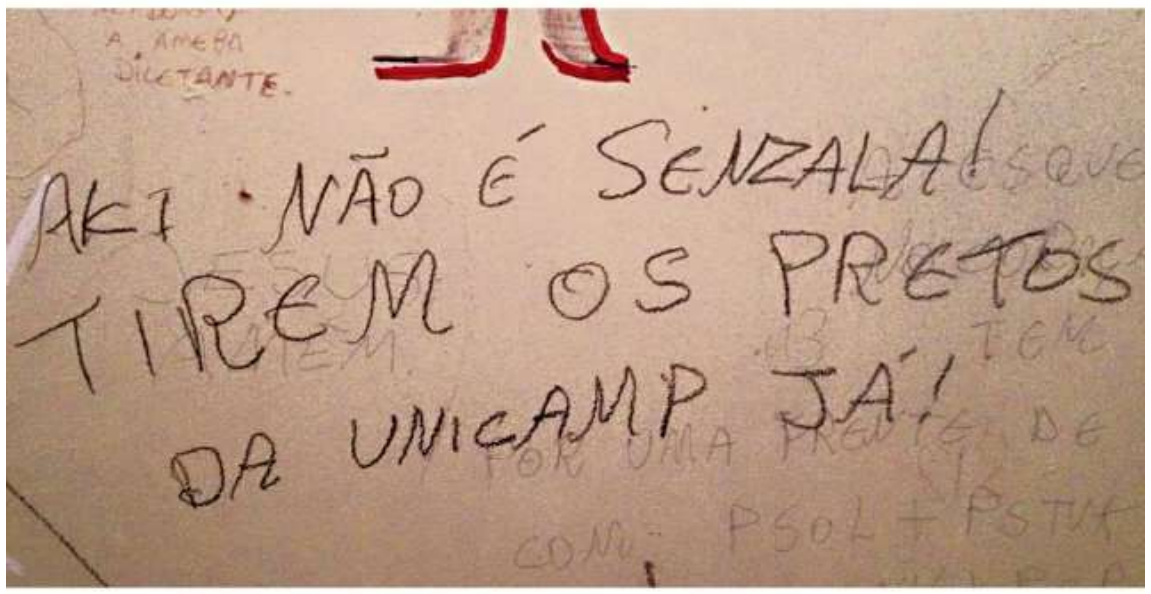

Pichação na parede do banheiro do IFCH - Unicamp (2016)

Figura 7

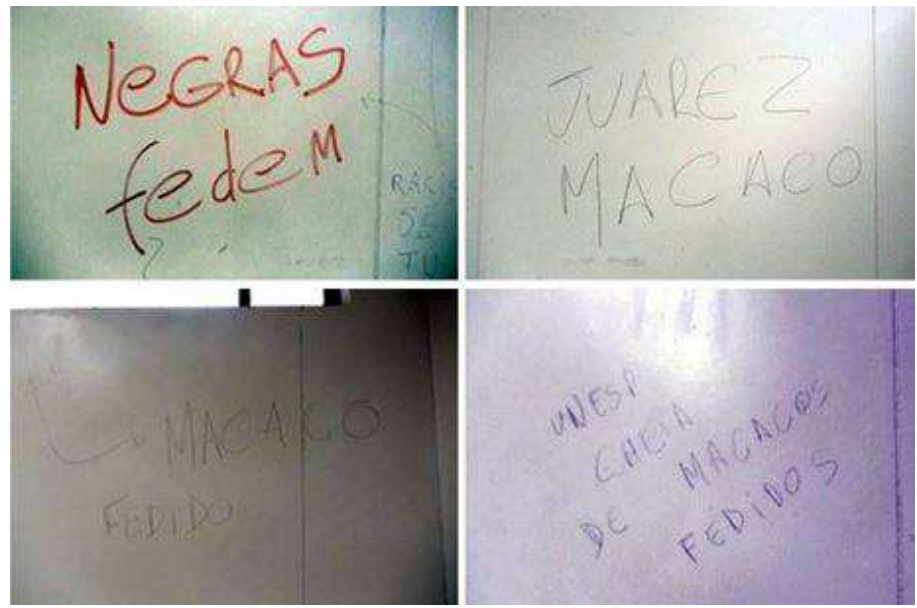

Pichação no banheiro da UNESP (2015)

\footnotetext{
12 ARAÚJO. Glauco. Alunos denunciam homofobia e racismo em faculdade do ABC Paulista. Disponível em: <https://g1.globo.com/sp/sao-paulo/noticia/alunos-denunciam-racismo-ehomofobia-em-faculdade-do-abc-paulista.ghtml>. Acessado em: 30 março. 2018. 00h05. https://www.geledes.org.br/estudantes-negros-respondem-pichacoes-racistas-na-unicamp/; MARCONI, Renata. Pichações racistas, homofobia e machistas. Disponível em: <http://g1.globo.com/sp/bauru-marilia/noticia/2015/11/pichacoes-racistas-homofobicas-emachistas-sao-encontradas-na-unesp.html>Acessado em: 30 março 2018. 00h10.
} 
A expressão do racismo não se faz presente apenas em contextos em que as cotas raciais são realidade, ele está presente também nas escolas de Ensino Fundamental como pode-se ver os trechos destinados abaixo.

Kauan é um menino de 11 anos que mora e estudo em São Paulo numa escola chamada João Vieira de Almeida. Publicou no Youtube um vídeo desabafando que sobre diariamente racismo em sua escola.

"Meu nome é Kauan Alvarenga, tenho 11 anos. Olha aqui, vou falar uma coisa para vocês [...] todo dia, todo santo dia, todo dia mesmo, eles mexem com meu cabelo, mexem comigo, e quando eu vou falar pra professora, [ela] não dá atenção, não fala nada, finge que não ouviu", explica Kauan."

Em um site chamado FORUM, criou uma Hashtag chamada \#MeuProfessorRacista, destacam alguns relatos chocantes entre alunos e professores. ${ }^{13}$

"\#MeuProfessorRacista O mais pesado que eu lembro agora. Ensino Fundamental, a diretora de um colégio conceituado do interior de São Paulo, uma carrasca fascista, fez um dos únicos alunos negros da sala

pegar o pão do lixo pra comer, na frente de toda a turma, pra ensinar "a não desperdiçar comida".

"\#meuProfessorRacista perguntou a um amigo negro de quem ele estava colando pra tirar tanta nota alta assim"

"\#MeuProfessorRacista falava que eu jamais podia ir para aula depois da Ed.Física pq pessoas da minha cor fediam com muita rapidez. $7^{\circ}$ série do Ensino Fundamental"

"\#MeuProfessorRacista me fez pedir desculpas e ABRAÇAR uma menina da sala que se recusava a brincar comigo porque o meu cabelo era ruim"

"\#MeuProfessorRacista disse na aula que preto tinha que fazer faculdade para, ao menos, ter cela especial quando fosse preso."

\#MeuProfessorRacista se recusou a ensinar a matéria mais uma vez e disse que para ser lavadeira não precisava entender matemática"

${ }^{13}$ LONGO. Ivan. Os relatos chocantes de racismo, preconceito e injúria racial em escolas e universidades. Disponível em: <https://www.revistaforum.com.br/meuprofessorracista-osrelatos-chocantes-de-racismo-preconceito-e-injuria-racial-em-escolas-euniversidades/>Acessado em: 05. Maio. 2018. 
Nos trechos acima, pode se perceber que os professores, que têm um papel importantíssimo no combate ao racismo, é, em alguns casos, os que praticam ou são coniventes com o preconceito racial em sala de aula, o que acaba contribuindo à manutenção e reforço da desigualdade social da população negra e, consequentemente, para sua baixa autoestima e, muitas vezes, da negação da própria imagem, sentimento de angustia e revolta, dificuldade de relacionamento e, consequentemente, para queda de rendimento escolar e evasão escolar, já que aquele ambiente, que deveria lhes servir de apoio para a transformação, acaba fazendo o contrário, oprimindo-o.

\section{O PAPEL DA ESCOLA DOS PROFESSORES E COMO TRABALHAR O RACISMO.}

O preconceito racial, que é o gatilho para a prática do racismo e da injúria racial, pode trazer inúmeros prejuízos ao ser humano, a grupos populacionais e à sociedade, muitas vezes, levando a consequências graves, principalmente na fase do desenvolvimento infantil. As questões pedagógicas acabam desestimulando os alunos a frequentarem os espaços escolares.

É importante que a escola seja um contexto livre de preconceitos e favorável para que todas as crianças possam ter direitos iguais, para que assim, elas possam se desenvolver no processo de aprendizagem com respeito e segurança. Dessa maneira, e por isso, o combate e a problematização ao preconceito racial nas escolas devem se dar desde a Educação Infantil, pois assim, a escola estará desempenhando, desde cedo, o seu principal papel social, que é o de transformar o mundo em um local mais justo possível, democrático e favorável ao desenvolvimento mais amplo possível do indivíduo enquanto ser social e cultural.

A educação que é direito de todos, o respeito às diferenças culturais. Alguns professores não sabem tratar o assunto de discriminação no espaço escolas e em sala de aula, nossa identidade cultural, de maneira a valorizar a contribuição os negros, e, na maioria das vezes, não se sentem capazes de ajudar os alunos que estão passando por situações discriminatórias.

Outra ferramenta importante na educação formal é o livro didático o qual acaba trazendo leituras e referências de mundo eurocêntrica, na qual a 
população negra entra como coadjuvante de uma história dos brancos, alimentando ainda mais os estereótipos raciais.

A presença dos negros nos livros, frequentemente como escravo, sem referência ao seu passado de homem livre antes da escravidão $e$ as lutas de libertação que desenvolveu no período da escravidão e desenvolveu hoje por direitos de cidadania, pode ser ocorrida se o professor contas a história de Zumbi dos Palmares, dos Quilombos, das revoltas e insurreições ocorridas durante a escravidão; contas algo do que foi a organização sócio-políticoeconômica e cultural na África pré-colonial; e também sobre a luta das organizações negras, hoje, no Brasil e nas Américas. (SILVA, 2005, Pg. 25)

Além dos livros didáticos, o currículo da disciplina História ${ }^{14}$ também reforça a ideia da desigualdade social pelo viés da cor de pele, pois transmite uma visão estereotipada da história da população negra, seja pela sua presença ou ausência ao longo dos conteúdos propostos. Dessa maneira, é importante que dirigentes professores e coordenadores de escolas estejam atentos a essa questão, seja para repensar a reelaboração desses materiais ou para trabalhálos de maneira crítica e com problematizações.

Enquanto as narrativas dos livros didáticos e do currículo forem pelo viés e olhar do branco, a principal estratégia é que os professores problematizem essas questões e busquem material que o apoie na empreitada da luta contra a discriminação e racismo, de maneira que não seja uma bandeira somente da população negra, mas de todos.

O ambiente escolar é um espaço que deve dar a todas as crianças condições de construir sua identidade e saber respeitar as diversidades sociais, culturais e econômicas. Conforme é notório sobre a função da Educação, é missão dos professores, não só preparar para o mundo acadêmico, mas também para a vida, então, dessa maneira é muito importante que esse trabalho comece desde as séries iniciais.

Reconhecendo a importância da cultura negra para a formação de nosso país, mas também que ela vem sendo negligenciada pela instituição escolar e

\footnotetext{
${ }^{14}$ Cabe lembrar que o currículo das demais disciplinas seguem uma linha branca normativa", passando a impressão que os seus domínios pertencem a cultura branca. O MEC disponibiliza material relacionado à Cultura Afrodescendente para todas as áreas do saber, entretanto, a grande maioria dos professores e escolas ignoram a sua existência.
} 
que tem trazido consequências negativas à comunidade negra, o governo brasileiro criou Leis para combater essas falhas, as quais tornam obrigatória a inclusão de História e cultura Afro-brasileira nos currículos escolares, desde a Educação Infantil ao Ensino Superior. Lê-se abaixo' ${ }^{15}$ :

O PRESIDENTE DA REPÚBLICA Faço saber que o Congresso Nacional decreta e eu sanciono a seguinte Lei:

Art. $1^{\circ}$ A Lei $n^{\circ}$ 9.394, de 20 de dezembro de 1996, passa a vigorar acrescida dos seguintes arts. 26- $A, 79-A e$ 79-B:

"Art. 26-A. Nos estabelecimentos de ensino fundamental e médio, oficiais e particulares, torna-se obrigatório o ensino sobre História e Cultura Afro-Brasileira.

$\S 1^{\circ}$ O conteúdo programático a que se refere o caput deste artigo incluirá o estudo da História da África e dos Africanos, a luta dos negros no Brasil, a cultura negra brasileira e o negro na formação da sociedade nacional, resgatando a contribuição do povo negro nas áreas social, econômica e política pertinentes à História do Brasil.

$\S 2^{\circ}$ Os conteúdos referentes à História e Cultura AfroBrasileira serão ministrados no âmbito de todo o currículo escolar, em especial nas áreas de Educação Artística e de Literatura e História Brasileiras.

"Art. 79-B. O calendário escolar incluirá o dia 20 de novembro como 'Dia Nacional da Consciência Negra'."

Art. $2^{\circ}$ Esta Lei entra em vigor na data de sua publicação.

Brasília, 9 de janeiro de 2003; $182^{\circ}$ da Independência e $115^{\circ}$ da República.

Essa Lei, assim como aquela, referente às cotas raciais, é uma tentativa de atenuar, as consequências históricas do nosso passado escravista e o racismo contra os negros que seguiu após a abolição da escravidão, e de tornar possível uma sociedade mais justa. No entanto, a Lei referente aos estudos da Cultura Afro ainda não é cumprida em todas as escolas e, até mesmo, em alguns concursos públicos não são cobrados o estudo da Lei em si, o que demonstra um certo descaso das autoridades com a questão.

Nas escolas, a aplicação de conteúdos relacionados à Cultura Afrodescendente não deve ser trabalhada apenas como forma de projeto ou em datas específicas, como por exemplo, o dia da "Consciência Negra", mas sim, deve fazer parte da rotina didática. A ideia é que sua aplicação também traga

\footnotetext{
${ }^{15}$ Lei 9.394 de 20 de dezembro de 1996. Disponível em: <http://www.planalto.gov.br/ccivil_03/leis/2003/l10.639.htm>Acessado em: 02. Abril. 2018.
} 
respeito às pluralidades étnicas e que possa criar uma sociedade mais justa e igualitária, dessa forma, é preciso que as ações não sejam direcionadas apenas aos alunos negros, mas para toda comunidade escolar, independentemente de sua cor ou condição social e cultural.

A falta de interesse, ou mesmo o desconhecimento, de algumas instituições e profissionais da área da educação acabam justificando que não tratam do assunto por falta de recursos, entretanto, o Ministério da Educação tem publicado e disponibilizado bastante material didático, não só de história como de outras disciplinas que traz assunto envolvendo questões relacionadas à população negra, tanto para apoio em sala de aula como para a formação de professores.

\section{CONSIDERAÇÕES:}

Buscou-se com o presente trabalho, que aborda questões relacionadas ao racismo e a possibilidades de combatê-lo no âmbito social e educacional, e entender o fenômeno de uma perspectiva histórica e social. Destarte, abordouse alguns aspectos da escravidão, de práticas racistas que vem ocorrendo em alguns contextos do Brasil atual e de iniciativas legais e institucionais para combate-lo.

Com relação às iniciativas de combater o racismo, destacou-se as ações afirmativas materializadas em Leis que "norteiam" implantações de políticas de "cotas raciais" nas universidades públicas, cujo objetivo é corrigir e compensar as desigualdades sociais que foram construídas historicamente em nosso país.

Pensou-se ainda na importância de se repensar os conteúdos de história nos currículos escolares e em materiais didáticos, de maneira que possibilite a reflexão e contribuição da diversidade étnica na construção da identidade brasileira.

Atualmente, percebeu-se que é necessário que se combata o preconceito no ambiente escolar e, para isso, é fundamental que os professores reconheçam a existência do racismo em sala de aula e estejam preparados para enfrenta-lo, de maneira que se promova um mundo mais justos a todos os cidadãos, independentemente de sua origem, classe social, crenças e cor de pele. Dessa forma, espera-se que este trabalho possa auxiliar nessa empreitada mais que justa à população negra que apesar de terem sido expostos a condições tão 
desfavoráveis ao longo da história, foi capaz de imprimir sua marca na construção material, espiritual, social e cultural de nosso país.

\section{REFERÊNCIAS BIBLIOGRÁFICAS:}

ALENCASTRO, Luís Felipe. O tratado dos viventes: formação do Brasil no Atlântico Sul - séculos XVI e XVII. São Paulo, Companhia das Letras, 2000.

ALVES, Cynthia Cristina De Souza. O racismo na escola e o combate com ações pedagógicas. Disponível em:

<http://dspace.bc.uepb.edu.br:8080/xmlui/bitstream/handle/123456789/1338/PDF\%20 20Cynthia\%20Cristina\%20de\%20Souza\%20Alves.pdf?sequence=1\&isAllowed=y>. Acessado em: 14 ago. 2017.

ANTINIL, André João. Cultura e Opulência no Brasil. Belo Horizonte/São Paulo, Editora Itatiaia/Edusp, 1982.

ARAÚJO. Glauco. Alunos denunciam homofobia e racismo em faculdade do ABC Paulista. Disponível em: <https://g1.globo.com/sp/sao-paulo/noticia/alunosdenunciam-racismo-e-homofobia-em-faculdade-do-abc-paulista.ghtml>. Acessado em: 30 março. 2018

CAVALHEIRO, Elaine. Educação anti-racista: compromisso indispensável para um mundo melhor. In: CAVALLEIRO, Elaine. Racismo e anti-racismo na educação: representando a nossa escola. São Paulo: Selo Negro, 2003.

CAVALLEIRO, Elaine dos Santos. Do silencio do lar ao silencio escolar: 6 ed. São Paulo - SP, 2014.

CÉLIA, Bruna. A mulher negra e pobre no Brasil.(2007) Disponível em:<http://www.overmundo.com.br/overblog/a-mulher-negra-e-pobre-no-brasil> Acessado em: 06 abril. 2018

CERDAN, Marcelo Alves. O tempo que os escravos tinham para si: Um estudo pobre autonomia escrava em Itu- de 1850 a 188. Franca, tese, UNESP, 2013.

DIWAN, Pietra. Raça Pura. São Paulo, Editora Contexto, 2007.

GUIMARÃES, Antônio Sérgio Alfredo. Preconceito e discriminação: 34 ed. São Paulo- SP, 2004.

HAAG, Carlos. Os ossos que falam. Disponível em: < http://revistapesquisa.fapesp.br/2011/12/24/ossos-que-falam/ > Acesso em abril. 2018 às $12 \mathrm{~h} 12$

LONGO. Ivan. Os relatos chocantes de racismo, preconceito e injúria racial em escolas e universidades. Disponível em:

$<$ https://www.revistaforum.com.br/meuprofessorracista-os-relatos-chocantes-deracismo-preconceito-e-injuria-racial-em-escolas-e-universidades/>Acessado em: 05. Maio. 2018. 
MARCONI, Renata. Pichações racistas, homofobia e machistas. Disponível em: <http://g1.globo.com/sp/bauru-marilia/noticia/2015/11/pichacoes-racistas-homofobicase-machistas-sao-encontradas-na-unesp.html>Acessado em: 30 março 2018.

MATTOSO, Kátia Queiros. Ser escravo no Brasil. S. Paulo, Editora Brasilense, 2003

PAVAN, Milena. As diferenças entre Racismo e Injúria Racial. (2016) Disponível em: <https://www.geledes.org.br/as-diferencas-entre-racismo-e-injuria-racial/> Acessado em: 06 abril. 2018.

RAMBELLI, Gilson. Arqueologia Subaquática em Cananéia. São Paulo, Editora Prisma, 2015.

ROSEMBERG, Fúlvia. Defasagem escolar, gênero e raça no Brasil: quem atrasa e quem conclui os estudos. 2011 Disponível em:

<https://ensaiosdegenero.wordpress.com/tag/fulvia-rosemberg/>. Acesso em: 04 abril. 2018.

RUGENDAS, J. Moritz. Viagem Pitoresca ao Brasil. São Paulo, Círculo do Livro, S/d.

SILVA, Ana Célia. A desconstrução da discriminação no livro didático. In:

MUNANGA, Kabengele. Superando o Racismo na escola. $2^{\circ}$ ed. Brasília: Ministério da Educação Continuada, Alfabetização e diversidade, 2005, p. 21-37.

SILVA, Maria Aparecida (Cidinha). Formação de Educadores/As para ao combate ao racismo: mais uma tarefa essencial. IN: CAVALLEIRO, Eliane. Racismo e AntiRacismo na Educação: repensando a escola. Selo Negro, São Paulo, 2001. sso em abril. 2018 às $12 \mathrm{~h} 12$ 